\title{
Influence of changes in hydrogeological conditions on industrial safety of buildings and structures
}

\author{
Margarita Yakovleva ${ }^{1 *}$, Evgeniy Frolov ${ }^{1}$, Veniamin Isayev $^{1}$, and Sergey Zubanov ${ }^{1}$ \\ ${ }^{1}$ Samara State Technical University Institute of Architecture and Civil Engineering, \\ 194, Molodogvardeyskaya St., 443001, Samara, Russia
}

\begin{abstract}
Technical condition surveys of a number of multi-purpose industrial facilities have shown that the hydrological conditions of the occupied sites often change in the course of operation. This is especially often observed in oil refining and petrochemical industries, the distinguishing feature of which is high water consumption for cleaning the machines and for general cleaning; with a low culture of the facility operation, water often flows out of the main water conduits, and when the drainage systems are disturbed, basement soils are steeped and plant territories are watered. This was observed even at sites where, at the time of the construction of the facility, the groundwater was buried deep enough and did not affect the surveyed building. Monitoring one of the processing plants made it possible to identify the source of flooding and investigate the nature of the change in the groundwater surface after long-term operation of the facility. The results of this work are given in this article.
\end{abstract}

\section{Introduction}

The main feature of oil refining and petrochemical industry is the presence of hydrocarbons in the technology, which have an increased explosion and fire hazard as well as a high combustion temperature of their products. In addition, the production technology is characterized by high water consumption, more than $10 \mathrm{~m}^{3}$ of water is necessary per $1 \mathrm{~m}^{3}$ of production.

Water and aqueous solutions are widely used for washing and testing technological apparatuses on external installations, in pedestal buildings and production plants, which leads to soaking the basements and foundations of the buildings and structures, and causes their premature aging [1], [2], [3] .

Trays are usually provided for water drainage, but eventually they fail, become clogged with rubbish, and streams of water and water solutions enter the basement grounds. Flooding of the industrial enterprise territory occurs even at sites where during construction the groundwater was deep and did not represent any threats to nature. After several years of operation, the groundwater level rose sharply, flooding the foundations of industrial buildings and structures. This phenomenon was observed by the staff of the branch research

* Corresponding author: md-63@yandex.ru 
laboratory "Reconstruction" in numerous surveys of such objects in the cities of Volgograd, Volzhsky, Solikamsk, Togliatti, Kursk, Samara and others [1], [4] - [6].

Water leaks when mixed with toxic materials lead to flooding of the territory and contamination of groundwater, causing damage to the environment and leading to economic losses.

Ground watering and the ways in which moisture may affect the foundation ground impact the industrial safety of buildings and structures.

It is known that the properties of ground largely depend on the relative content of water in them.

Water content in the ground does not remain constant, but depends on the inflow of capillary moisture that fills the pores of the ground partially or completely at the required height from the level of flowing groundwater.

Capillary moistening of ground primarily affects its mechanical strength.

\section{Materials and methods}

Groundwater is divided into subground water, groundwater, spring water and water of technological origin.

The site under consideration is characteristic of ground and subground water. Subground water is seasonal in nature and is often short-lived.

Ground water is a supported gravity moisture, located entirely in the ground thickness; it is capable of flowing out of the sections, but does not have a hydraulic connection with the underlying groundwater. Excessive water can, however, flow down into the underlying layers of rocks. A variety of ground water is open groundwater, i.e. the accumulation of water caused by the location of slightly water-permeable layers of clay, alluvial horizons in the ground.

Groundwater lies below the ground layer on the first waterproof layer of the ground from the day surface; it is not blocked by water permeable rock and is the source of capillary waters.

Capillary waters become one of the main sources of moistening and destruction of underground structures of buildings.

Capillary phenomena arise in structures depending on the kind of material, temperature conditions, physical, chemical and biological destructive processes.

Groundwater also includes waters of technical origin, which can appear in the course of leaks from technological production water lines and sewage systems, as well as from water vapour condensate in the ground.

The phenomenon of water rising through the capillaries is especially often manifested with negative temperatures, when ice crystals are formed in large pores of the soil. The structure of frozen grounds changes with the degree of freezing.

The main causes of moisture migration are as follows:

- osmotic forces that arise in the form of the suction force of the solution in the presence of a temperature gradient (the higher the gradient, the greater the forces);

- stresses caused by uneven freezing;

- capillary forces.

Migration of moisture at negative temperatures is also observed in materials of structures, foundations and walls [7], [8].

Underground waters always contain dissolved gases and minerals. The waters can be soft or hard depending on the content of dissolved mineral particles.

The hardest water is found in carbonate rocks.

Soft waters are characterized by a large dissolving capacity (aggressiveness) when concrete, mortars and many other silicate materials are exposed to them. 
The most common of acidic corrosive waters is carbon dioxide containing oxygen dioxide (CO2), which produces carbon dioxide as compound with water.

$$
\mathrm{CO}_{2}+\mathrm{H}_{2} \mathrm{O}=\mathrm{H}_{2} \mathrm{CO}_{3}
$$

The more free carbon dioxide there is in the water, the stronger is its aggressiveness.

Among aggressive waters are those containing organic acids, for example, humic acids of marsh waters, destroying concrete.

Water containing sulphate acids and chlorine is also aggressive.

Humid-aggressive effects of groundwater influence both the foundations and the base [9], [10].

The most soluble bases are those composed of limestones, dolomites and gypsum; the least soluble are igneous and clayey rocks.

The choice of a solution to protect the foundations from the effects of groundwater is based on studying the factors that cause a change in the groundwater regime.

These factors are divided into natural and artificial.

Natural factors are related to the features of the geological structure, climate, terrain and the development of the hydrographic network. The nature of rocks bedding and their lithological composition affect the groundwater regime to a greater extent. When slightly permeable rocks are located close to the day surface, underflooding is very likely. The same rocks contribute to the formation and retention of capillary water.

Seasonal and annual fluctuations in the groundwater level are associated with climatic factors. When percolating through layers containing soluble salts, waters that are not chemically harmful often turn into aggressive ones.

Without a proper drainage system and with a waterproof layer at a shallow depth, water accumulations can cause waterlogging of the terrain.

Changes in the atmospheric pressure also affect the fluctuations in the groundwater level. The change in the level occurs simultaneously with the change in atmospheric pressure and consists in the partial or complete transformation of capillary water into gravitational and, vice versa, (with decrease in pressure) in the increase of the capillary level due to the partial transfer of gravitational water to capillary water.

The filtration action of a groundwater stream directed downwards sometimes causes large ground settlement and considerable deformation in the buildings.

Upward movement of moisture can occur due to evaporation process as well as a rise in the groundwater level.

It should be noted from the foregoing that at the surveyed site the following phenomena can occur in the presence of groundwater level:

- fluctuations in the groundwater level;

- compaction of base grounds with lowering of groundwater level;

- soaking and swelling of the ground layer with increasing groundwater level;

-freeze heaving and freezing of wet ground with foundations;

- destructive changes in foundation materials under the influence of aggressive agents.

\section{Results}

We carried out an examination at one of the enterprises of the city of Samara to study the nature of flooding of the plant site where a high groundwater level was found during the piercing of the object foundation. To study the dynamics of changes in the level of the groundwater surface, we carried out monitoring, designed for a long service life. After studying the documentation, a working program was drawn up, according to which we planned the sites for drilling boreholes in the ground and for placing casing pipes. 
Drilling of boreholes was carried out with a manual drill with a diameter of $140 \mathrm{~mm}$. The depth of drilling depended on the depth of the waterproof layer and the level of groundwater. Soil samples with broken structure were taken in the process of drilling boreholes from a depth of up to four meters and delivered to a ground laboratory, where the characteristics of soil plasticity were determined.

It has been established that the soils of the base are clay loams from soft-plastic to flowing ones, as well as flowing sandy loams (Table 1).

Table 1. List of soil properties

\begin{tabular}{|c|c|c|c|c|c|c|c|c|c|}
\hline 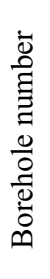 & 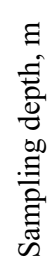 & 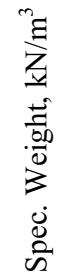 & 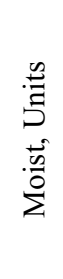 & 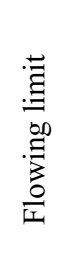 & 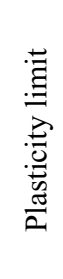 & 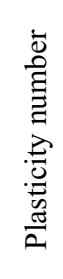 & $\begin{array}{l}\underset{0}{0} \\
. \Xi \\
.00 \\
. \\
\frac{0}{1} \\
\frac{0}{I}\end{array}$ & 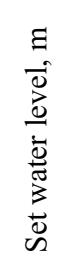 & 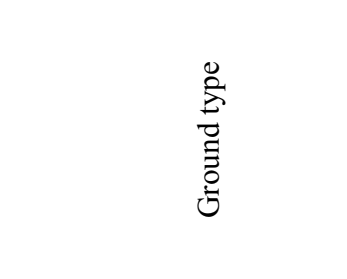 \\
\hline 1 & 4,0 & 27,1 & 0,22 & 0,26 & 0,16 & 0,1 & 0,60 & 3,71 & soft-plastic clay loams \\
\hline 2 & 4,0 & 27,0 & 0,19 & 0,18 & 0,14 & 0,04 & 1,25 & 2,59 & flowing sandy loams \\
\hline 3 & 2,0 & 27,1 & 0,30 & 0,35 & 0,18 & 0,17 & 0,71 & 0,64 & soft-plastic clay loams \\
\hline 4 & 4,0 & 27,1 & 0,22 & 0,24 & 0,16 & 0,08 & 0,75 & 1,03 & soft-plastic clay loams \\
\hline 7 & 4,0 & 27,1 & 0,22 & 0,24 & 0,15 & 0,09 & 0,77 & 2,40 & flowing-plastic clay loams \\
\hline 8 & 4,0 & 27,1 & 0,25 & 0,31 & 0,16 & 0,15 & 0,60 & 1,52 & soft-plastic clay loams \\
\hline 11 & 4,0 & 27,1 & 0,25 & 0,24 & 0,17 & 0,07 & 1,14 & 2,00 & flowing clay loams \\
\hline 12 & 4,0 & 27,1 & 0,24 & 0,25 & 0,16 & 0,09 & 0,89 & 2,03 & flowing-plastic clay loams \\
\hline 13 & 4,0 & 27,1 & 0,31 & 0,31 & 0,17 & 0,14 & 1,00 & - & flowing-plastic clay loams \\
\hline 14 & 4,0 & 27,1 & 0,30 & 0,30 & 0,16 & 0,14 & 0,93 & 2,05 & flowing-plastic clay loams \\
\hline 15 & 4,0 & 27,0 & 0,22 & 0,22 & 0,16 & 0,06 & 1,00 & 1,78 & flowing sandy loams \\
\hline 16 & 4,0 & 27,1 & 0,24 & 0,29 & 0,17 & 0,12 & 0,58 & 2,25 & soft-plastic clay loams \\
\hline 17 & 4,0 & 27,1 & 0,23 & 0,24 & 0,15 & 0,09 & 0,89 & 2,17 & flowing-plastic clay loams \\
\hline 18 & 4,0 & 27,1 & 0,25 & 0,28 & 0,16 & 0,12 & 0,75 & 2,56 & soft-plastic clay loams \\
\hline 19 & 4,0 & 27,0 & 0,20 & 0,20 & 0,16 & 0,09 & 1,00 & 2,18 & flowing sandy loams \\
\hline
\end{tabular}

The layout of the observation boreholes is shown in Figure 1. The depth of the borehole was $4 \mathrm{~m}$, and the casing pipes are made of two separate elements $2 \mathrm{~m}$ each. Holes with a pitch of $250 \mathrm{~mm}$ were drilled in staggered order in the wall of the lower pipe. The upper pipe is without holes. The design of borehole completion is given in Figure 2. 


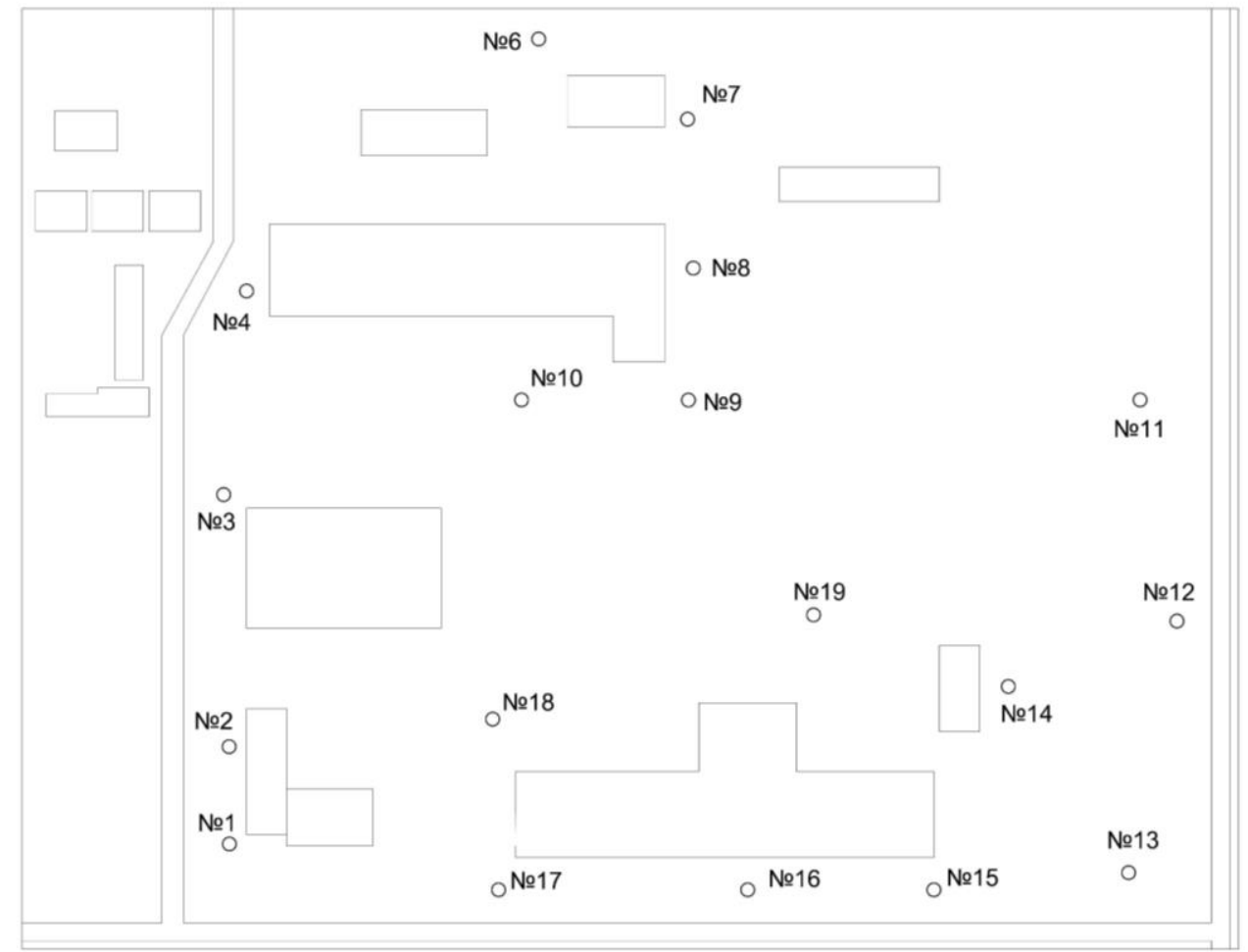

Fig.1. The layout of control boreholes at the industrial site 2000 мм

a.

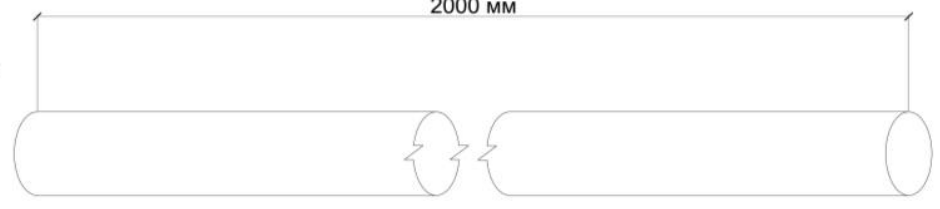

B.

2000 MM

б.
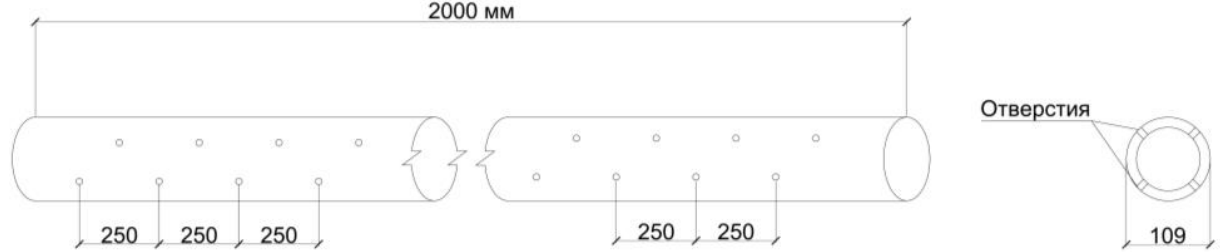

Fig.2. Casing design for monitoring groundwater level. a) - the upper part of the pipe; б) the lower part of the pipe with holes; в) the lid.

Both pipes (Fig. 3b) were lowered into the borehole drilled in the ground (Figure 3a). A special cover is provided from above to prevent clogging of the pipe. The groundwater level was measured by measuring dipstick, the results of measurements were recorded in a special register. Figure 4 shows a pipe with a lid installed in place. 
a)

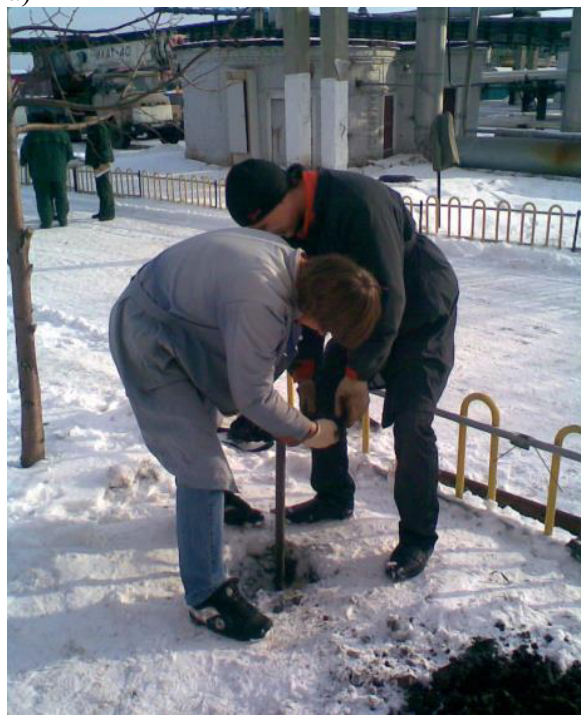

b)

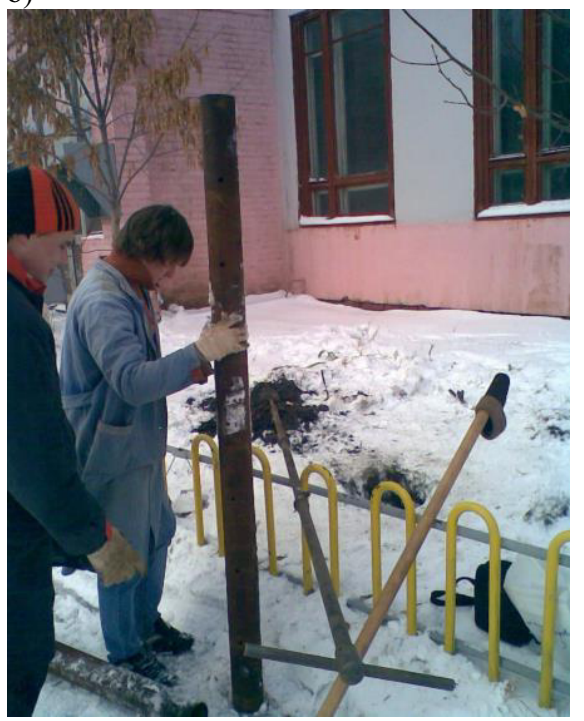

Fig. 3. a) Drilling the borehole b) Installing the lower casing pipe into the borehole.

Monitoring of the groundwater level was carried out on a quarterly basis. Data showed the following results during the two years period (Table 2).

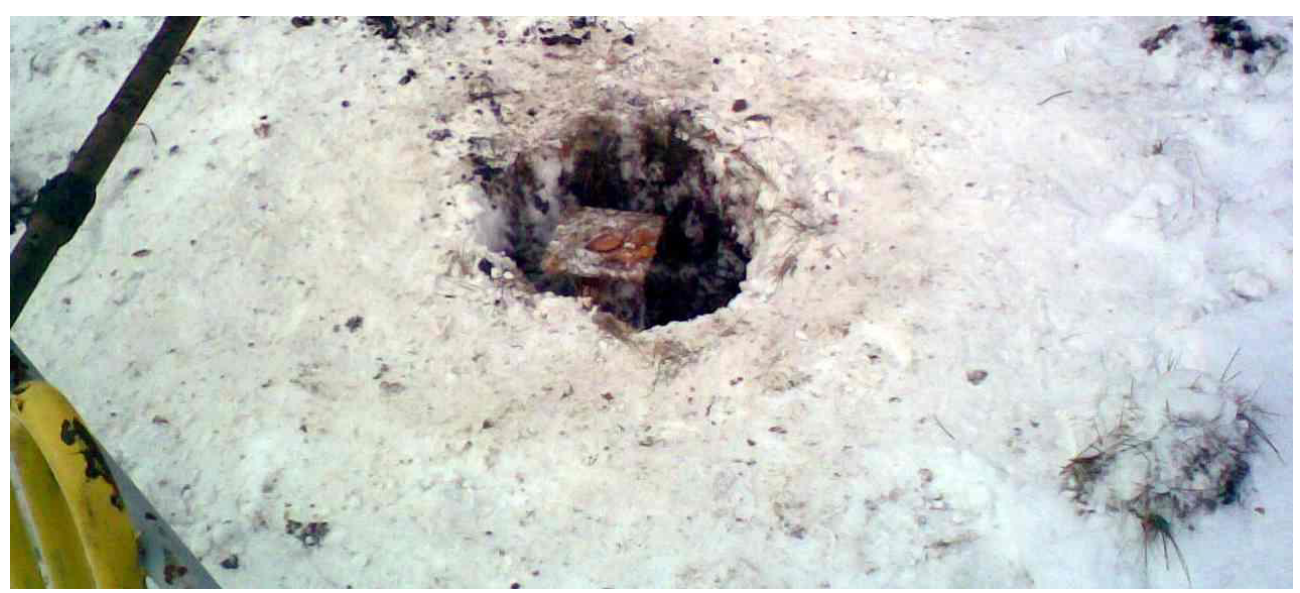

Fig. 4. The borehole is equipped. The pipe is closed with a special lid.

Table 2. Measurement of the groundwater level from the ground surface, $\mathrm{m}$.

\begin{tabular}{|c|c|c|c|c|c|c|c|c|c|c|}
\hline Period & \multicolumn{10}{|c|}{ Borehole number } \\
\cline { 2 - 12 } & 1 & 2 & 3 & 4 & 5 & 6 & 7 & 8 & 9 & 10 \\
\hline Year 1 & 3,71 & 2,59 & 0,64 & 1,03 & - & 2,48 & 2,40 & 1,52 & 2,47 & 2,58 \\
\hline Year 2 & 3,58 & 3,45 & 1,30 & 2,0 & - & 2,42 & 2,44 & 1,92 & 2,58 & 2,72 \\
\hline & 11 & 12 & 13 & 14 & 15 & 16 & 17 & 18 & 19 & \\
\hline Year 1 & 2,00 & 2,03 & - & 2,05 & 1,78 & 2,25 & 2,17 & 2,56 & 2,18 & \\
\hline Year 2 & 1,85 & 1,76 & - & 1,93 & 1,51 & 1,36 & - & 2,48 & 1,63 & \\
\hline
\end{tabular}




\section{Discussion}

Analysing the results of the work performed on the production site, which are partially given in Tables 1 and 2, we make the following conclusions:

- water-bearing materials (grounds) on the entire survey site are soft-plastic clay loams;

- the established level of groundwater within the object is located at a depth of more than $2 \mathrm{~m}$;

- boreholes №3, 4 and 8 have a dome-shaped rise in the groundwater level;

- a seasonal change in the water level within 0.5-1.0 $\mathrm{m}$ was noted based on the results of long-term tests,;

- groundwater did not rise above the ground freezing level;

- sources of flooding were identified;

- water surface measurement data from the industrial site is taken into account when designing new facilities with a deep foundation level.

\section{Conclusions}

Installing a system of hydrological observations in the form of a field of boreholes with special casing pipes at operating industrial sites enabled us to control the dynamics of fluctuations in the rise of groundwater. This makes it possible to prevent flooding of individual units of large enterprises through timely protective measures.

These observations are especially important during reconstruction, repair work or modernization.

\section{References}

1. M.V. Yakovleva, O.N. Kotkova, Estimation of the Change in the Load-Bearing Capacity of Building Structures during Operation: Guidelines (Samara State University of Architecture and Civil Engineering, Samara, 2009)

2. Rules for Inspection of Load-Bearing Building Constructions of Buildings and Structures (State Committee for Construction of Russia, Moscow, 2004)

3. Buildings and Structures. Rules for Inspection and Monitoring Technical Condition. (State Committee for Construction of Russia, Moscow, 2011)

4. F. Parkins, Reinforced Concrete Structures. Waterproofing Repair and Protection (Moscow, 1980)

5. M.V. Yakovleva, E.A. Frolov, A.E. Frolov, K.I. Gimadetdinov, Inspection of the Technical Condition of Buildings and Structures: Training Manual (Samara State University of Architecture and Civil Engineering, Samara, 2011)

6. M.V. Yakovleva, E.A. Frolov, A.E. Frolov, Building Construction. Preparation, Reinforcement, Protection against Corrosion (Forum, Moscow, 2015)

7. Dobromyslov A.N. Diagnosis of Damage to Buildings of Engineering Structures. (ASV Publishing House, Moscow, 2006)

8. Ushakov I.I., Bondarev B.A. Fundamentals of Diagnostics of Building Structures (Phoenix Publishing House, Rostov-on-Don, 2008)

9. Manual for Monitoring the State of Metal Constructions of Buildings and Structures in Aggressive Environment. Carrying out Surveys and Designing Corrosion Protection (Stroiizdat, Moscow, 1989) 
10. Recommendations for the Inspection and Monitoring the Technical Condition of Existing Buildings Located near New Construction or Reconstruction (Moscow Commission of Construction and Architecture, Moscow, 1998) 